\title{
Ocular Drug Delivery Targeting the Retina and Retinal Pigment Epithelium Using Polylactide Nanoparticles
}

\author{
Jean-Louis Bourges, ${ }^{1,2,3}$ Sandrine E. Gautier, ${ }^{4}$ Florence Delie, ${ }^{5}$ Riad A. Bejjani, ${ }^{1,2}$ \\ Jean-Claude Jeanny, ${ }^{1,2}$ Robert Gurny, ${ }^{5}$ David BenEzra, ${ }^{6}$ and Francine F. Behar-Cohen ${ }^{1,2,3}$
}

Purpose. To study the kinetics of polylactide (PLA) nanoparticle (NP) localization within the intraocular tissues and to evaluate their potential to release encapsulated material.

Methods. A single intravitreous injection $(5 \mu \mathrm{L})$ of an NP suspension $(2.2 \mathrm{mg} / \mathrm{mL})$ encapsulating either Rh-6G (Rh) or Nile red $(\mathrm{Nr})$ was performed. Animals were killed at various times, and the NPs localization within the intraocular tissues was studied by environmental scanning electron microscopy (ESEM), confocal microscopy, light microscopy histology, fluorescence microscopy, and immunohistochemistry. Eyes injected with blank NPs, free Rh, or PBS solution were used as the control.

Results. ESEM showed the flow of the NPs from the site of injection into the vitreous cavity and their rapid settling on the internal limiting membrane. Histology demonstrated the anatomic integrity of the injected eyes and showed no toxic effects. A mild inflammatory cell infiltrate was observed in the ciliary body 6 hours after the injection and in the posterior vitreous and retina at 18 to 24 hours. The intensity of inflammation decreased markedly by 48 hours. Confocal and fluorescence microscopy and immunohistochemistry showed that a transretinal movement of the NPs was gradually taking place with a later localization in the RPE cells. Rh encapsulated within the injected NPs diffused and stained the retina and RPE cells. PLA NPs were still present within the RPE cells 4 months after a single intravitreous injection.

Conclusions. Intravitreous injection of PLA NPs appears to result in transretinal movement, with a preferential localization in the RPE cells. Encapsulated Rh diffuses from the NPs and stains the neuroretina and the RPE cells. The findings support the idea that specific targeting of these tissues is feasible. Furthermore, the presence of the NPs within the RPE cells 4 months after a single injection shows that a steady and continuous delivery of drugs can be achieved. (Invest Ophthalmol Vis Sci. 2003;44:3562-3569) DOI:10.1167/iovs.02-1068

From ${ }^{1}$ Unit 450 of the National Institute of Health and Medical Research (INSERM U450) and the ${ }^{2}$ Rothschild Foundation, Paris, France; the ${ }^{3}$ Department of Ophthalmology, Hôtel-Dieu of Paris, France; the ${ }^{4}$ Centre for Studies and Research into Macromolecules, Biomaterial Institute, University of Liege, Liege, Belgium; the ${ }^{5}$ School of Pharmacy, Geneva University, Geneva, Switzerland; and the ${ }^{6} \mathrm{Hadassah}$ Hebrew University Hospital, Jerusalem, Israel.

Supported in part by grants from The Foundation for the Future and the French Ophthalmology Society.

Submitted for publication October 17, 2002; revised December 29, 2002; accepted Febriary 1, 2003.

Disclosure: J.L. Bourges, None; S.E. Gautier, None; F. Delie, None; R.A. Bejjani, None; J.C. Jeanny, None; R. Gurny, None; D. BenEzra, None; F.F. Behar-Cohen, None

The publication costs of this article were defrayed in part by page charge payment. This article must therefore be marked "advertise ment" in accordance with 18 U.S.C. $\$ 1734$ solely to indicate this fact.

Corresponding author: F. F. Behar-Cohen, INSERM U450, 15 rue de l'Ecole de Médecine, 75006 Paris, France; behar@idf.inserm.fr.
Tong-term delivery of biologically active molecules to the $\triangle$ neuroretina and/or to the retinal pigment epithelium (RPE) is problematic and remains a challenge. To increase the bioavailability, prolong controlled release of molecules, and avoid repeated intraocular surgical procedures, the possible use of various biodegradable polymeric particles has been extensively investigated. Among these, the slowly degradable aliphatic polyesters (polylactides; PLAs) are of particular interest. The PLAs are biocompatible and can be synthesized in various molecular sizes and conformations allowing for the encapsulation of specifically adapted formulations. Their degradation rate depends on the polymer's molecular weight, conformation, and copolymer composition. ${ }^{1,2}$ Encapsulation of molecules within PLAs preserves the molecular integrity of proteins and oligonucleotides and prevents their rapid in vivo degradation. ${ }^{3-6}$ Encapsulation of DNA plasmid within PLAs has also been shown to preserve their in vivo functional integrity. ${ }^{7}$

The intracellular delivery to specific tissues of molecules encapsulated within aliphatic PLA nanoparticles (NPs) opens a wide range of therapeutic avenues. Indeed, in vitro and in vivo studies have shown that NPs can be internalized by mononuclear and polymorphonuclear phagocytes ${ }^{8,9}$ and intestinal epithelial cells. ${ }^{10}$ For ocular applications, NPs have been used mostly to increase the intra ${ }^{1}{ }^{11}$ and transcorneal ${ }^{12}$ penetration of drugs. Poly ( $\epsilon$-caprolactone) NPs $(210 \mathrm{~nm})$ have been shown to be internalized in corneal epithelial cells after incubation of the rabbit cornea in vitro or after their instillation as drops in vivo. ${ }^{13}$

In the present study we observed the kinetics of intraocular tissue and cellular localization after a single intravitreous injection of PLA NPs in normal rat eyes.

\section{Materials ANd Methods}

Poly(D,L-lactides) NPs were labeled by encapsulation of two fluorochromes, Rh-6G (Rh, positively charged) and Nile red (Nr; neutral). These two fluorochromes have different water solubility $(54$ and $3 \times$ $10^{-4} \mathrm{~g} / \mathrm{L}$, respectively) and affinity toward PLA. Before intravitreous injection, the stability and release rates of $\mathrm{Rh}-6 \mathrm{G}$ and $\mathrm{Nr}$ from the encapsulating NPs were studied in vitro.

\section{Preparation of Rh-6G-Loaded PLA NPs}

Rh-6G-loaded PLA NPs were prepared by nanoprecipitation from dimethyl sulfoxide (DMSO), as described elsewhere. ${ }^{14}$ Briefly, $64 \mathrm{mg}$ of poly(D,L-lactides; R-206, $\mathrm{M}_{\mathrm{n}}=48 \mathrm{kDa}$, and $\mathrm{M}_{\mathrm{w}} / \mathrm{M}_{\mathrm{n}}=1.8$, BoehringerIngelheim, Ingelheim, Germany), $640 \mu \mathrm{g}$ of a methacrylate random copolymer P(MMA-co-MA $\mathrm{MA}_{12}$ ) that contained 12 mole percent (mol\%) methacrylic acid $\left(M_{n}=24 \mathrm{kDa}, \mathrm{M}_{\mathrm{w}} / \mathrm{M}_{\mathrm{n}}=1.2\right)$ and $2.2 \mathrm{mg} \mathrm{Rh}-6 \mathrm{G}$ (Sigma-Aldrich, Buchs, Switzerland) were dissolved in $4 \mathrm{~mL}$ DMSO. Phosphate buffer ( $25 \mathrm{~mL}$ of $0.13 \mathrm{M}, \mathrm{pH} 7.4)$ was rapidly added to the polymer solution with no additional stirring. The suspension was first dialyzed against water (cutoff, 6000-8000; Spectra/Por; Spectrum Medical Industries, Los Angeles, CA), precipitated at acidic $\mathrm{pH}$ to remove nonencapsulated $\mathrm{Rh}$ and then resuspended in $32 \mathrm{~mL}$ of phosphate-buffered saline (PBS; $0.13 \mathrm{M}, \mathrm{pH} 7.4, \mathrm{NaCl} 0.9 \%$ ).

The total Rh concentration (Rh sequestered in the NPs plus the free $\mathrm{Rh}$ in the suspension) determined by UV-visible spectrometry after 
dissolution of the lyophilized suspension in DMSO (max absorption wavelength in DMSO: $538 \mathrm{~nm}$ ) was $59 \mu \mathrm{g} / \mathrm{mL}$. The free nonencapsulated $\mathrm{Rh}$ determined in the supernatant after centrifugation at 14,000 $\mathrm{rpm}$ at neutral $\mathrm{pH}$, was $2 \mu \mathrm{g} / \mathrm{mL}$. Although the total Rh loading differed slightly in the various NP preparations, in most the free Rh concentration in the supernatant was $3.3 \%$ of the total Rh with an Rh loading in the NPs of approximately 2.5 weight percent (wt $\%$ ).

The stability of Rh encapsulation was evaluated in storage conditions (i.e., $+4^{\circ} \mathrm{C}$ ), and the release of Rh from PLA/PMMA-co-MA NPs was studied at $+37^{\circ} \mathrm{C}$ as follows. A newly prepared suspension of 1.9 mg of NPs per milliliter of balanced salt solution (BSS; Alcon, Fort Worth, TX) containing a total of $42.3 \mu \mathrm{g} / \mathrm{mL} \mathrm{Rh}$ was stored at $+37^{\circ} \mathrm{C}$ for 30 days. The suspension was then diluted 20 times and stored at $+37^{\circ} \mathrm{C}$ for 36 days. At regular intervals $(0,10$, and 30 minutes; 1,2 , and 3 hours; and 1, 4, 6, 8, 11, 15, 19, 27, 30, and 36 days), $500 \mu \mathrm{L}$ of each suspension was sampled. The NP suspension was precipitated by ultracentrifugation, and the Rh concentration in the supernatant was measured by UV-visible spectrometry.

The mean diameter of the NPs measured by dynamic light scattering (Brookhaven argon laser $488 \mathrm{~nm}$; Brookhaven Instruments, Ltd, Redditch, UK; "contin" calculation method) was $140 \pm 20 \mathrm{~nm}$. The $\zeta$ potential in PBS measured by Doppler electrophoretic light scattering (Delsa 440; Coulter, Hialeah, FL) was $-60 \mathrm{mV}$.

\section{Preparation of Nr-Loaded PLA NPs}

PLA (Medisorb $100 \mathrm{DL}, \mathrm{M}_{\mathrm{w}}$ : $100 \mathrm{kDa}$ ) was obtained from Medisorb Technology International L.P. (Cincinnati, OH). Poly(vinyl alcohol) (PVAL Mowiol 4-88, $\mathrm{M}_{\mathrm{w}}: 2.6 \mathrm{kDa}$, Hoechst, Frankfurt am Main, Germany) was used as a stabilizer. $\mathrm{Nr}$ was obtained from Sigma-Aldrich. NPs were prepared according to a single-emulsion/solvent-evaporation method. ${ }^{15}$ Briefly, the polymer was dissolved in methylene chloride $(150 \mathrm{mg} / \mathrm{mL})$. Thirty microliters of a $0.2 \%$ solution of $\mathrm{Nr}$ in methylene chloride was added to $1 \mathrm{~mL}$ of the polymer solution. This organic solution was emulsified by sonication (Vibracell Sonics and Materials, Danbury, CT) in $2 \mathrm{~mL}$ of a $2 \%$ PVAL aqueous solution for 30 seconds at $50 \mathrm{~W}$. This emulsion was then poured in $50 \mathrm{~mL}$ PVAL $1 \%$ solution and mechanically stirred (Eurostar; IKA Labortechnik, Staufen, Germany) at a rate of $1200 \mathrm{rpm}$. The emulsion was first maintained for 1 hour at $+4^{\circ} \mathrm{C}$ and then at room temperature for 3 hours. After solvent evaporation, particles were washed by centrifugation and lyophilized in the presence of $50 \mathrm{mg}$ of trehalose to help particle resuspension after lyophilization. ${ }^{16}$ Particle size and morphology were assessed by photon correlation spectrometry measurements (Zetasizer 5000; Malvern Instruments, Ltd., Malvern, UK) as well as scanning electron microscopy (SEM; JSM-6400; JEOL, Tokyo, Japan). The mean size was $310 \pm$ $40 \mathrm{~nm}$ and the $\zeta$ potential determined in water was $-4.6 \pm 0.6 \mathrm{mV}$.

A dye loading of $0.32 \mu \mathrm{g} / \mathrm{mg}$ was determined by spectrofluorometry (excitation $544 \mathrm{~nm}$, emission $595 \mathrm{~nm}$ : using a luminescence spectrometer (LS-50B; Perkin Elmer, Rotkreuz, Switzerland) after PLA solubilization in methylene chloride.

The release of $\mathrm{Nr}$ was studied in vitro at $+37^{\circ} \mathrm{C}$ as follows. NPs were suspended in balanced salt solution $(70 \mathrm{mg} / 35 \mathrm{~mL})$ and kept at $+37^{\circ} \mathrm{C}$ for 28 days. At regular intervals $(0,1,6,18,24,48$ hours; 7,14 , 28 days), $1 \mathrm{~mL}$ of the suspension placed in different vials was sampled and centrifuged and the $\mathrm{Nr}$ concentration measured in the supernatant and in the pellet (Fig. 2).

\section{Animals}

Eighty-eight male Lewis rats, 12 weeks old and weighing $200 \mathrm{~g}$, were used in these experiments (IFFA CREDO, Lyon, France). Experiments were conducted in accordance with the ARVO Statement for the Use of Animals in Ophthalmic and Vision Research. Rats were held in the vivarium for 1 week before the experiments began and were anesthetized with pentobarbital intraperitoneal injection $(40 \mathrm{mg} / \mathrm{kg})$. At the end of the experiments, rats were killed by injection of a lethal dose of pentobarbital.

\section{Intravitreous Injections}

Before in vivo injection, the PLA NP suspensions, prepared as described earlier were centrifuged at $3000 \mathrm{rpm}$ for 3 minutes to remove large aggregates formed potentially during the preparation process. The supernatant containing the particles was then collected and used for the injections. The right eyes of the experimental animals received an intravitreous injection of $5 \mu \mathrm{L}$ of Nr- or Rh-loaded NPs, blank NPs, or free Rh, or balance saline (BSS; Alcon) through a 30-gauge needle inserted at 11 o'clock, $2 \mathrm{~mm}$ posterior to the limbus. Eyes were examined by indirect ophthalmoscopy after pupil dilation immediately after the intravitreous injection. In two eyes a vitreous hemorrhage was observed after the procedure. Those eyes were excluded from the study.

All solutions used for the preparation of the NP solutions and those used for the intravitreous control injections were sterile and toxin-free.

\section{Experimental Design}

Rats received an intravitreous injection of $5 \mu \mathrm{L}$ of NPs (adjusted to a concentration of $2.2 \mathrm{mg} / \mathrm{mL}$ ) loaded either with $\mathrm{Rh}$ or $\mathrm{Nr}$ and killed at intervals of 1, 6, 18, 24, and 48 hours and 4 weeks after the injection. Control rats received an intravitreous injection of $5 \mu \mathrm{L}(0.4 \mu \mathrm{g} / \mathrm{mL})$ free $\mathrm{Rh}$ and were killed at the same time points and in parallel with the experimental animals. Four rats (four eyes) were used for each treatment (or control) group at every time point ( 72 eyes of 72 rats).

Eyes were submitted to confocal scanning laser microscopy studies immediately after enucleation. Fluorescence microscopy and immunohistochemistry were performed on snap-frozen eyes. Histology was performed after fixation in $4 \%$ paraformaldehyde. Two to four control eyes were also included and studied in parallel at each time point.

Three-dimensional examination of the vitreous and retinal surface was performed on freshly enucleated eyes 10 minutes and 1 hour after the injection (two eyes per time point) using environmental scanning electron microscopy (ESEM).

\section{Confocal Microscopy}

Immediately after the eyeball dissection, unfixed flatmounted retina and retinal pigment epithelium (RPE)-choroid-sclera were clover cut and observed by confocal microscopy (Laser Scanning System LSM510; Carl Zeiss Meditech, Oberkochen, Germany). Slices were digitized on the totality of the thickness of each sample. Images were obtained either by phase contrast (Nomarski mode) or fluorescence at $543 \mathrm{~nm}$. Superposition was used for image analysis.

\section{Immunohistochemistry}

Eyes were enucleated, snap frozen, embedded in optimal cutting temperature (OCT) compound (Tissue-Tek; Sakura Finetek, Leiden, The Netherlands), and kept at $-80^{\circ} \mathrm{C}$. Cryosections (7-10 $\mu \mathrm{m}$ thick) were prepared and stored at $-20^{\circ} \mathrm{C}$. Defrosted slides were then dipped in $0.1 \%$ Triton in phosphate-buffered saline (PBS), rinsed in PBS, and incubated in 5\% skimmed milk for 1 hour. Sections were then incubated in humidified atmosphere at room temperature for 1 hour with the following specific antibodies at 1:50 (in PBS, 1\% skimmed milk, 0.5\% Triton): monoclonal mouse anti-rat ED1 staining myeloid cells such as macrophages (Serotec, Oxford, UK); monoclonal mouse anti-rat OX42/CD11b staining microglia, dendritic cells, granulocytes, and macrophages (Serotec); polyclonal rabbit anti-bovine glial fibrillary acidic protein (GFAP) staining astrocytes and activated Müller cells (DAKO, Glostrup, Denmark); and monoclonal mouse anti-rat anti-pan cytokeratin (CytoK) staining epithelial cells. After a 1-hour incubation with the antibodies, slides were washed with PBS and incubated for 1 hour with rabbit anti-mouse IgG or monkey anti-rabbit IgG biotinylated antibodies. The slides were then rinsed with PBS and overlaid with a fluorochrome-conjugated streptavidin sheep anti-rabbit IgG or bovine anti-monkey IgG antibodies.

Sections were finally rinsed in PBS, mounted in antifade medium (Vectashield; Vector Laboratories Inc., Burlingame, CA), and observed 
by fluorescence photomicroscopy (FXA Microphot; Nikon, Melville, NY). Digitized micrographs were obtained with a camera (Spot; BFI Optilas, Evry, France).

\section{Environmental Scanning Electron Microscopy}

For ESEM, freshly enucleated eyes were dissected at the pre-equatorial level and the posterior eye cup was directly observed under the microscope (XL 30 ESEM-FEG; Philips Electron Optics, Eindhoven, The Netherlands). ${ }^{17}$ The ESEM maintains the sample in an examination chamber at high pressure $(>10 \mathrm{~mm} \mathrm{Hg})$ and the emission signal is amplified by gas detection. When compared with a regular scanning electron microscope, the advantage of ESEM is its ability to enable visualization and scrutiny of large areas of the vitreous body and retinal surface in situ.

\section{Results}

\section{Loading and Release Kinetics of PLA NPs}

NPs of different diameters and surface charge were obtained: $140 \pm 20 \mathrm{~nm}$ and $-60 \mathrm{mV}$ for Rh-loaded PLA PMMA-co-MA NPs and $310 \pm 40 \mathrm{~nm}$ and $-6 \mathrm{mV}$ for the $\mathrm{Nr}$ PLA PVLA-covered NPs.

When stored at $+4^{\circ} \mathrm{C}$, Rh NPs (Rh NPs) showed a concentration of free $\mathrm{Rh}$ ranging from $7 \%$ to $9 \%$ of total $\mathrm{Rh}$, over the study period (Fig. 1a). The same behavior was observed when NPs were stored at $+37^{\circ} \mathrm{C}$ (Fig. 1b). Free Rh was far from its water solubility $(54 \mathrm{mg} / \mathrm{mL})$ indicating that $\mathrm{Rh}$ release was limited. This limitation was probably the result of the electrostatic interactions between the quaternary amine of Rh-6G and the sodium carboxylate group of the PMMA-co-MA copolymer, leading to a high affinity of the Rh to the NPs. At 36 days, $84 \%$ of Rh was still associated with the NPs in the diluted suspension stored at $+37^{\circ} \mathrm{C}$. When the suspension was 20 -fold diluted, free $\mathrm{Rh}$ in the solution increased from $9 \%$ to $21 \%$ within 10 minutes after dilution (Figs. 1c, 1d).

$\mathrm{Nr}$ release from PLA NPs at $+37^{\circ} \mathrm{C}$ showed an initial limited burst release followed by a very low release rate during 30 days of $0.4 \%(0.07 \mu \mathrm{g} / \mathrm{mL}$; Fig. 2). This profile indicates the high affinity of $\mathrm{Nr}$ for PLA and is also influenced by the very low water solubility of $\mathrm{Nr}\left(3 \times 10^{-4} \mathrm{mg} / \mathrm{mL}\right)$.

\section{Fluorescence and Confocal Microscopy}

One hour after injection, Rh NPs were observed within the vitreous (Fig. 3a) and settling on the internal limiting membrane (ILM; Fig. 3b). No NPs were detected in the retina at this time point (Figs. 3c, 3d). Six hours after injection, Rh NPs were still present on the retinal surface (Fig. 4a) and were observed also within the deeper retinal layers. A few NPs were identified at the level of the ganglion cells layer (GCL; Fig. 4b), the rod outer segments (ROS; Fig. 4c), and even within the retinal pigment epithelium (RPE; Fig. 4d). A mild diffuse red staining due to Rh release from the encapsulating NPs was also observed on the retinal surface and in the RPE layer (Fig. 4d).

Approximately 18 to 24 hours after the intravitreous injection, fluorescence and confocal microscopy showed that the NPs were accumulating preferentially within the RPE cells (Figs. 5a, 5d). At this stage, fewer NPs were seen in the vitreous, on the ILM (Fig. 5b), within the GCL, or in the inner nuclear layers (not shown). A relatively large number of NPs were detected, however, within the ROS (Fig. 5c). An evident diffuse red staining was present in the retina, ROS, and RPE (Fig. 5) that was due to the release of encapsulated Rh. At later time points and up to 4 months after a single intravitreous injection, Rh NPs were still observed within the RPE cells. Fluorescence microscopy of flatmounted choroid-RPE complexes (after having removed the neuroretina) showed a clear red granular staining due to the presence of Rh NPs within the RPE cell cytoplasm (Fig. 6). At this time point, however, along with the remaining intact NPs, partly hydrolyzed "fuzzy" NPs were also observed within the RPE cells. Rhodamine from these degrading NPs and Rh leaking from the other intact NPs conferred a marked diffuse red staining on the neural retinal tissues and particularly to the RPE cells.

After injection, the NPs diffused from the vitreous cavity in all directions. During the first month after the intravitreous injection, a sizable number of the injected NPs were observed attached to the posterior capsule of the lens, in the iris and ciliary body, and within the vitreous. Four months after the injection, however, no defined NPs were observed within the vitreous cavity. Most of the detected particles are localized within the intraocular tissues and concentrated in the RPE cell layer.

When free Rh was injected into the vitreous (Fig. 7), a red diffuse staining was observed in the ROS and the RPE at 6 (Figs. $7 \mathrm{c}, 7 \mathrm{~d}$ ) and 24 (Figs. $7 \mathrm{~g}, 7 \mathrm{~h}$ ) hours. No granular formations characteristic of the images observed after injection of NPs were seen. This diffuse red staining of the intraocular tissues faded gradually and could hardly be detected 1 week after the intraocular injection of free $\mathrm{Rh}$.

When Nr NPs were injected into the vitreous, the pattern of intraocular distribution was similar to that of the Rh NPs, except for the sharper appearance of the Nr NPs and the absence of diffusion of free fluorochrome.

Injection of blank NPs or PBS did not induce any specific granular or diffuse tissue staining. Because of the absence of fluorochrome, the observation of blank NP migration and behavior was more difficult to follow.

\section{Histology and Immunohistochemistry}

One hour after intravitreous injection of the NPs, no infiltrating cells were observed in the ciliary body, in the retina, or at the retinal surface (Fig. 8a). Six and 24 hours after the injection a few infiltrating cells were observed in the vitreous cavity and in the retina (Figs. 8b, 8c). During these later time points, ED1and $\mathrm{OX}-42-$ positive cells were visible in the ciliary body, the posterior vitreous, and the internal retinal layers (Figs. 9a, 9b, $9 \mathrm{~g}, 9 \mathrm{~h})$. The number of both types of infiltrating cells increased markedly 24 hours after the injection (Figs. 9c, 9d, 9i, 9j). At 48 hours however, the number of positively stained cells for both markers decreased (Figs. 9e, 9f, 9k, 91). A similar pattern of inflammatory reaction was also observed in eyes injected with blank NPs or PBS solution. The costaining with red (Rh-6G) and green (ED1 and OX-42) illustrates that some of the infiltrating cells engulfed the NPs (Figs. 9d, 9j, insets).

One, 6 (not shown), and 24 hours after injection, GFAPpositive cells were observed throughout the retina. GFAPpositive staining was nonspecific, with similar patterns observed with both loaded NPs and PBS injections. It was not possible to assess whether the GFAP-positive cells ingested the injected NPs (Figs. 10a, 10c).

Cytokeratin-positive cells (RPE) demonstrated unequivocally a clearly defined granular red staining (Rh NPs) within the cytoplasm 24 hours after the injection (Fig. 10d and inset).

\section{Environmental Scanning Electron Microscopy}

The vitreous-retinal interface was examined on freshly excised eye cups after the intravitreous injection of NPs. Aggregates of NPs with individual NP configuration was well visualized (Fig. 11a). Furthermore, ESEM visualized the flow of NPs from the injection site and its repartition on the retinal surface (Fig. 11b). 
Figure 1. Percent of free Rh in suspension of PLA/PMMA 12 90:10 (wt: wt) NPs over time. The solution was stored at $+4^{\circ} \mathrm{C}$ (a) or $+37^{\circ} \mathrm{C}$ (b) or stored at $+37^{\circ} \mathrm{C}$ and diluted 20 -fold (c). (d) Release of free Rh during the first 3 hours in the undiluted suspension stored at $+37^{\circ} \mathrm{C}(\mathbf{\Delta})$, and in the 20-fold diluted suspension $(\diamond)$.
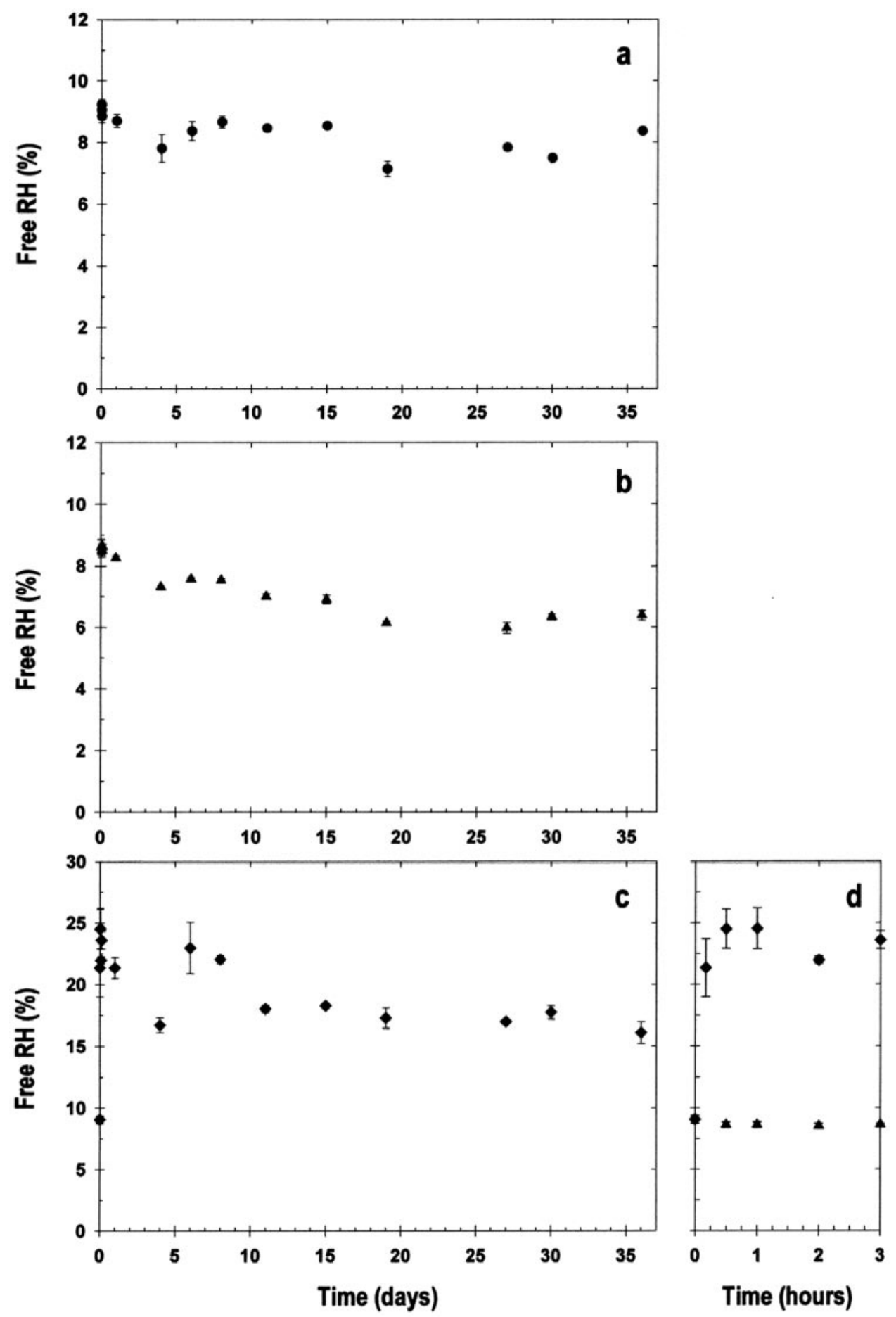

tions of these findings may be the opening of a novel avenue for drug delivery targeted to the posterior segment of the eye in general and to RPE cells and retina in particular. Furthermore, our observations show the presence of NPs within the RPE cells up to 4 months after a single intravitreous injection. This system could be modulated to serve as a method of extended slow delivery of drugs and/or plasmids for the treatment of chronic diseases and for genetic therapy. ${ }^{18}$ However, these observations apply to the rat's eye and possible differences with the human eye have to be taken in consideration when basing any drug delivery system based on these findings. Recently, it has been reported that nonbiodegradable polysty- 


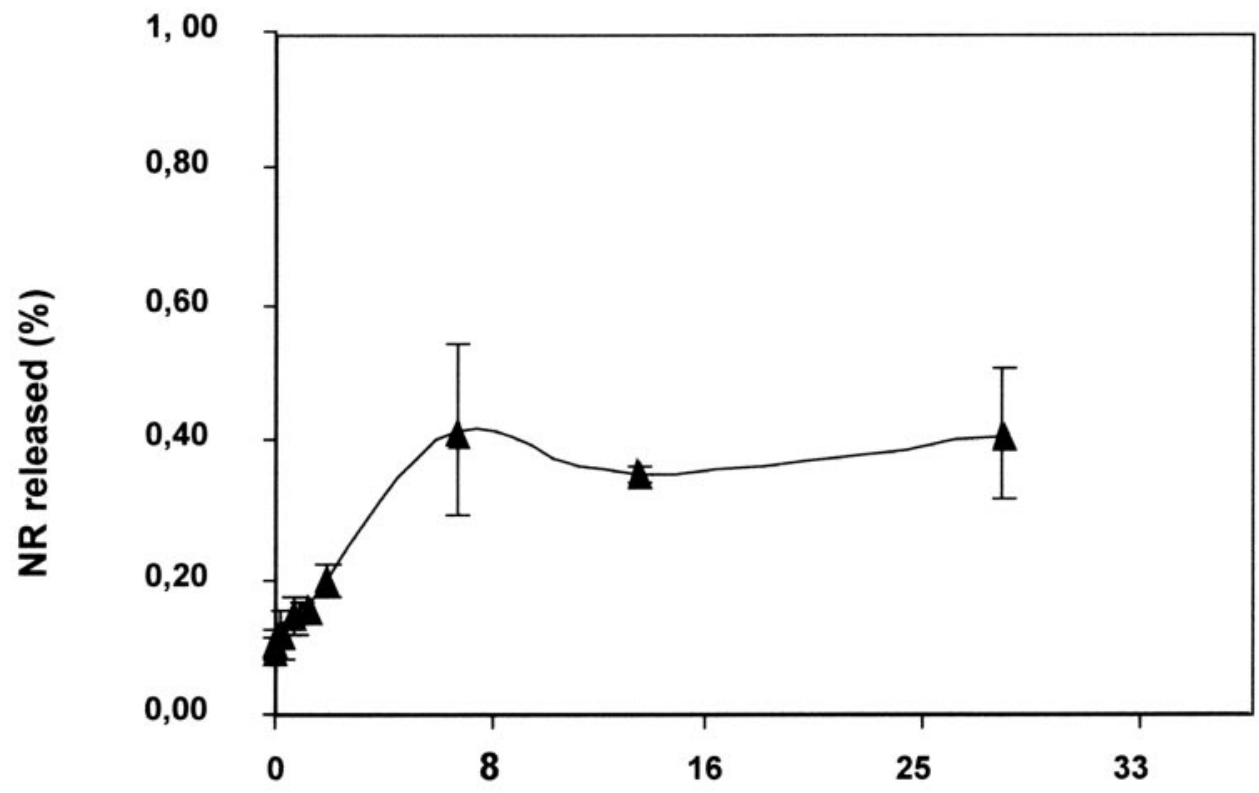

Time (days)

rene nanospheres $(<2 \mu \mathrm{m})$ were still observed within the neuroretina and in the RPE 2 months after a single intravitreous injection in rabbits. ${ }^{19}$ These later findings and the observations in the present study demonstrate that a transretinal movement of particles takes place in vivo. In our experiments, the relatively rapid transretinal movement of the used NPs may have been facilitated by the following:

1. A rupture of the ILM physiological barrier due to a modification of the vitreous interface structure secondary to the presence of the PLA and PLGA.

2. The inflammatory reaction after the injection may also have contributed to the ease of transretinal movement of the NPs.

3. Activation of the retinal microglial cells may have modified the permeability and anchoring mechanism on the ILM.

4. The molecular weight threshold for penetration into the retina through the ILM has been evaluated for molecules but not for spherical formations. It is reasonable to assume that the behavior of NPs is different from that of a protein. In this regard, we observed by electron microscopy that NPs used in the present study were able to cross the basal membrane of the corneal epithelium (data not shown).

In our study, we followed the kinetics of tissue and cellular localization of two different sizes of NPs loaded with either Rh or Nr. Different chemical interactions are taking place between the NP polymers and these fluorochromes. Rh diffuses rapidly from the PLA NPs as shown by the in vitro release kinetics and the in vivo behavior after their intravitreous injection. $\mathrm{Nr}$, in contrast, remained mostly within the encapsulating NPs, staining little or none of the infiltrated tissues. The distribution kinetics of the different NPs were very similar, however, showing that the NPs' electric charge and size have little influence on the intraocular tissue distribution of these sub-350-nm particles. The Rh dye diffused from the NPs and stained the targeted tissues evenly. The retinal and RPE NPs, identified as spherical images both by confocal and fluorescence micros-
Figure 2. Percent of free $\mathrm{Nr}$ in suspension of PLA NPs stored at $+37^{\circ} \mathrm{C}$ for 28 days.
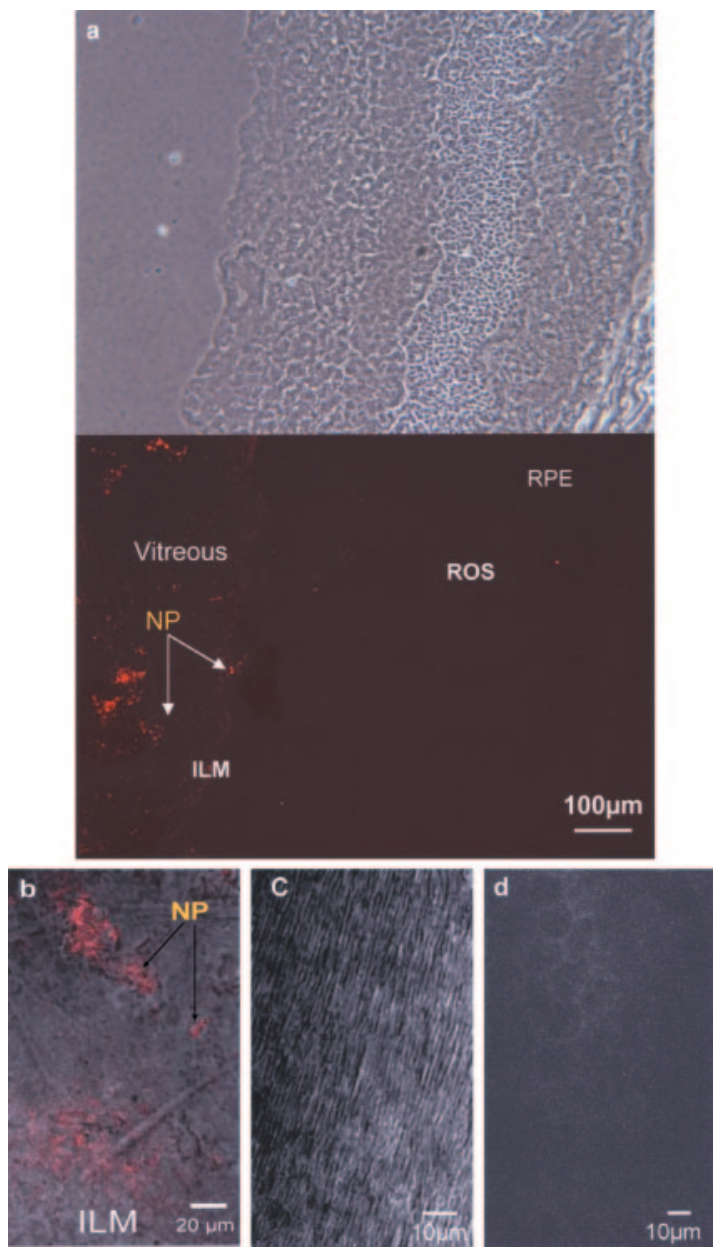

Figure 3. One hour after intravitreous injection of Rh NPs $(5 \mu \mathrm{L}, 2.2$ $\mathrm{mg} / \mathrm{mL}$ ). Fluorescence microscopy of the retina (a). Confocal microscopy of the retina showing the ILM (b), ROS (c), and RPE cells (d). 

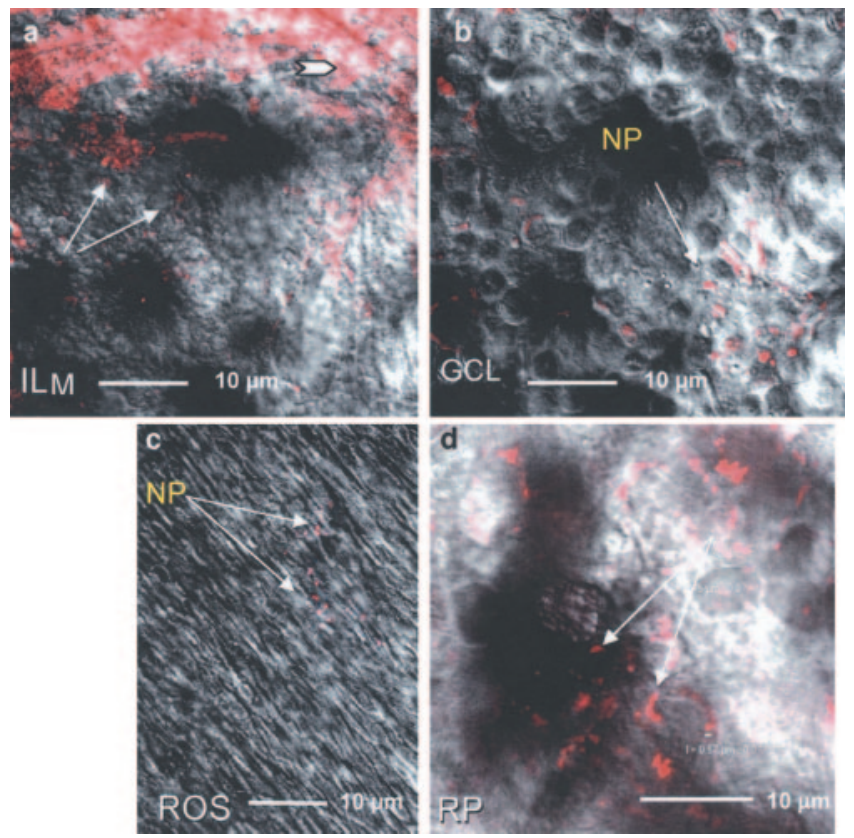

FIGURE 4. Six hours after intravitreous injection of Rh NPs $(5 \mu \mathrm{L}, 2.2$ $\mathrm{mg} / \mathrm{mL}$ ). Confocal microscopy of the retina showing the ILM (a), the GCL (b), the ROS (c) and the RPE (d).

copy, localized in the different retinal layers and released the sequestered dye to the retinal tissues. In the inner retinal layers and in the ROS, we were unable to determine whether the NPs were inside the cells or in the intercellular spaces. In the RPE cells however, NPs were clearly identified inside the cytoplasm by confocal microscopy. RPE cells are apparently able to ingest microspheres in vitro or after in vivo subretinal injection of these larger particles. ${ }^{20,21}$ When inside the RPE cells, NPs degraded slowly and were observed on freshly mounted RPE eyes 4 months after injection. At this time point, free $\mathrm{Rh}$ released from the NPs and that originating from partially degraded NPs may have reattached to lysosomal vesicles within

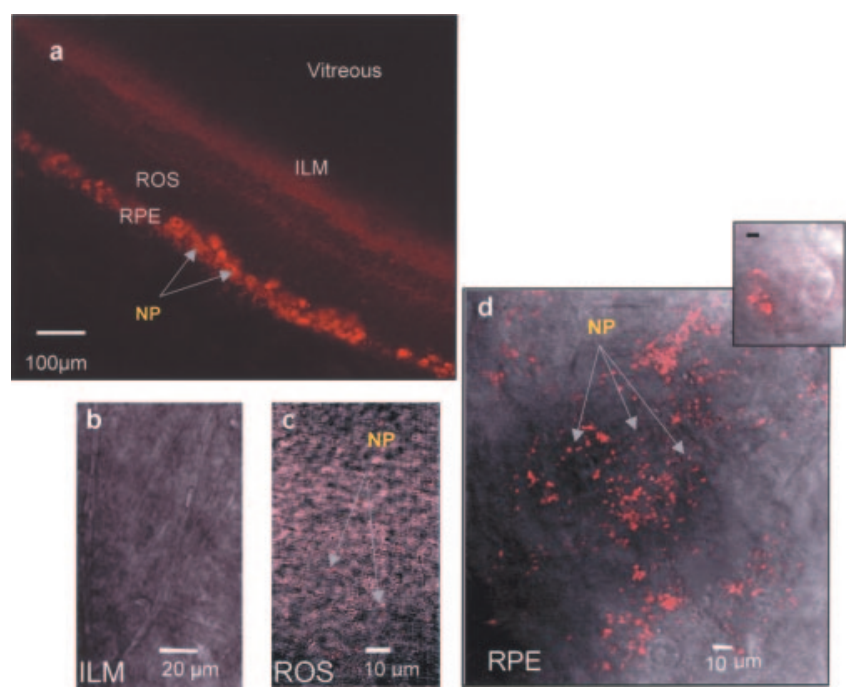

Figure 5. Twenty-four hours after intravitreous injection. Fluorescence microscopy of the retina (a) showing extensive accumulation of NPs in the retina. Note the diffuse red staining of the inner retinal layers due to free Rh released from the injected NPs. Confocal microscopy showing that the ILM (b) was free of NPs. The ROS (c) and the RPE cells (d) harbored large numbers of NPs.

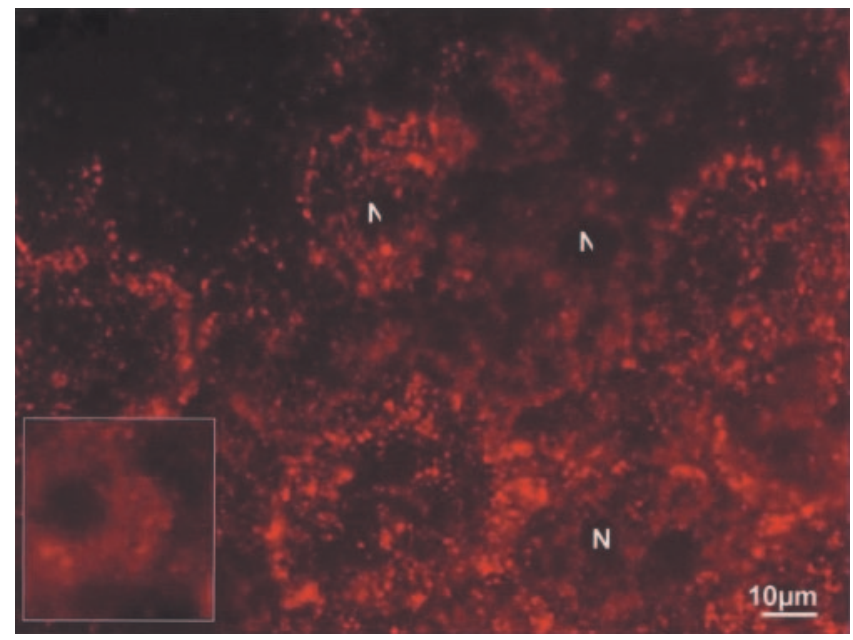

FigURE 6. Flatmount RPE-choroid complex at 4 months after a single intravitreous injection of Rh NPs showing the RPE cells still filled with the engulfed fluorescent NPs (arrowheads). Diffusion of free Rh (nonaggregate red staining) was also observed (inset). $\mathrm{N}$, nucleus.

the RPE cells, contributing to the particulate appearance within these cells.

For intraocular delivery of drugs, intravitreous injections are a more practical and clinically applicable route of delivery than subretinal injections. Therefore, the possible intravitreous injection of small NPs is very attractive.

Immediately after intravitreous injection, ESEM revealed that the particles spread slowly on the retinal surface, forming aggregates, with a preferential accumulation in "hot spots" in some places.

PLA seems to be better tolerated than PLGA in vivo. ${ }^{21-24}$ In our study, it appeared that at least part of the inflammatory infiltrate observed after injection of the NPs was due to trauma. Control eyes also showed a mild inflammatory cell infiltration shortly after injection. The same activation of retinal glial and Müller cells, as illustrated by the staining intensity to GFAP was observed in the eyes receiving NPs and in the control eyes. Thus, the intraocular penetration of the needle was probably responsible for this nonspecific reaction. Whether this GFAPpositive cell activation played any role in the transretinal move-
RPE
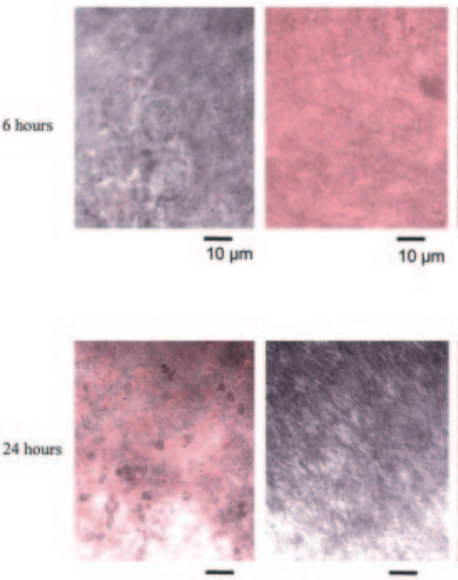

$\overline{10} \mu \mathrm{m}$
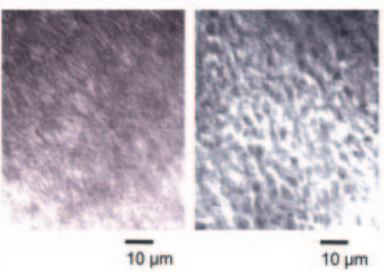

ILM
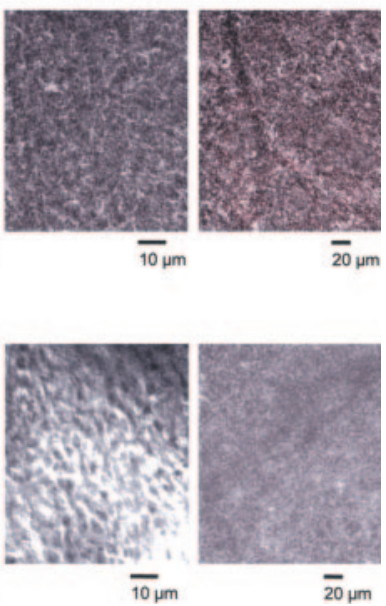

Figure 7. Confocal microscopy of the retina at 6 and 24 hours after intravitreous injection of free $\mathrm{Rh}(5 \mu \mathrm{L} ; 0.4 \mu \mathrm{g} / \mathrm{mL})$. The free Rh slowly diffused through the retinal layers and stained the RPE. 

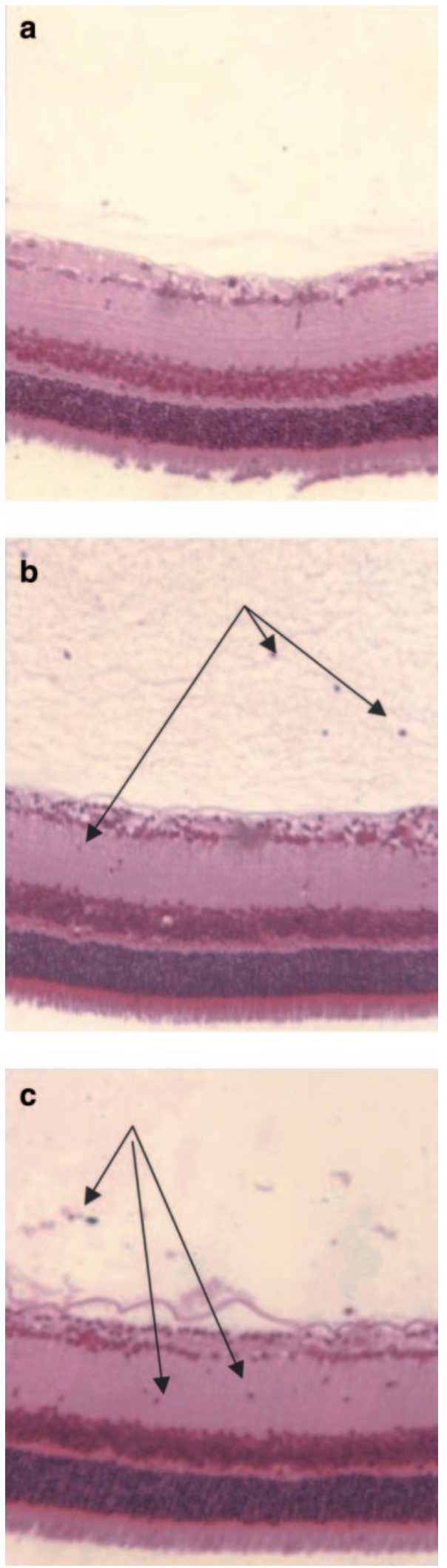

Figure 8. Histology of the retina at 1 (a), 6 (b), and 24 (c) hours after injection of $5 \mu \mathrm{L} \mathrm{Rh} \mathrm{NPs}(2.2 \mathrm{mg} / \mathrm{mL})$. Note the absence of any significant cellular infiltration at 1 hour and the increased number of cells observed within the vitreous and the retina (b, c, arrows) at 6 and 24 hours after the injection.
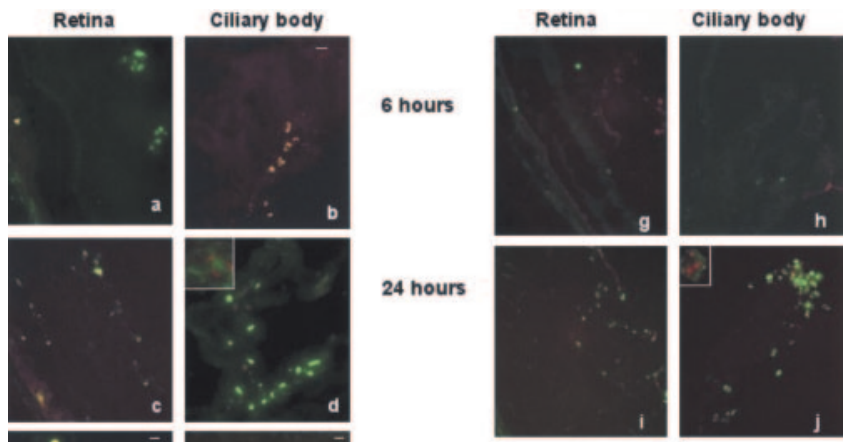

24 hours
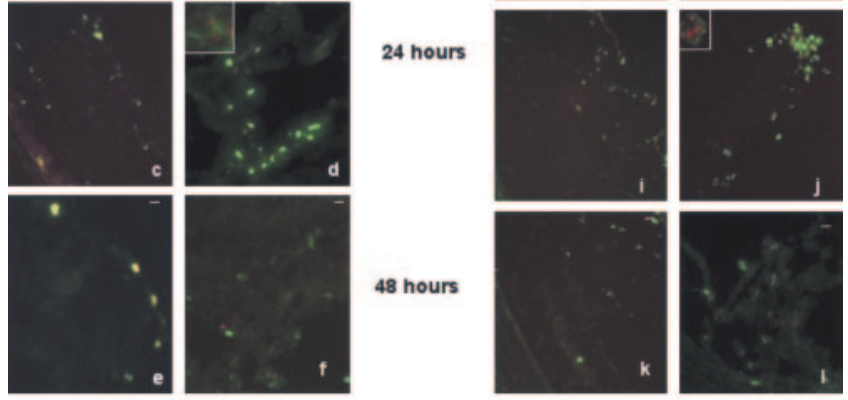

ox42

FIGURE 9. Immunohistochemistry of the retina and the ciliary body at 6, 24, and 48 hours after injection. Infiltrating OX42- and ED1-positive cells are green. The NPs fluoresced in red. OX42- or ED1-positive cells engulfing the NPs were costained and fluoresced in yellow.

ment of the NPs remains to be evaluated. Moreover, it would be of interest to determine whether anti-inflammatory treatment after injection would influence the intraocular distribution of NPs.

The anatomy and tissue integrity were well preserved after the intravitreous injection of the studied NPs loaded with fluorochromes. It is undeniable, however, that before clinical implementation of this type of drug delivery system, the possible influence on retinal function and vision has to be tested. Electroretinographic studies of these influences in rats are now ongoing in our laboratory.

In conclusion, the injected NPs reach the retina rapidly, homing in on the RPE cells where they were still observed 4 months after the injection. Encapsulated Rh-6G dye diffused slowly from the NPs and uniformly stained the retinal layers.

\section{GFAP}
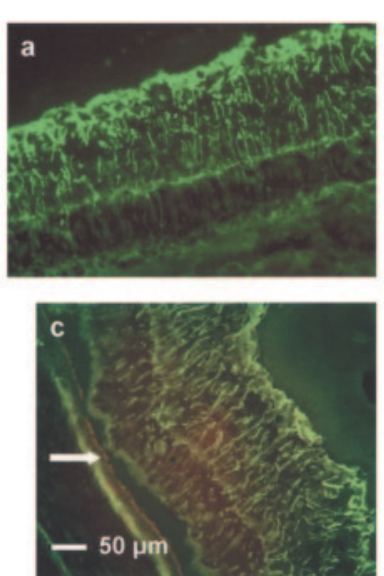

\section{Cytokeratin}
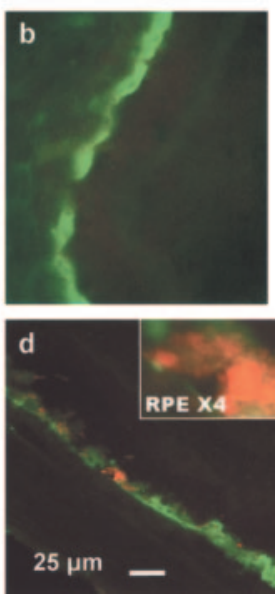

FigURE 10. Immunohistochemistry of the retina $1(\mathbf{a}, \mathbf{b})$ and 24 hours (c, d) after injection. Staining for cytokeratin $(\mathbf{b}, \mathbf{d})$ demonstrated accumulation of NPs within the RPE cells. This was best illustrated at 24 hours (c, white arrow: $\mathbf{d}$, inset). GFAP-positive cells were nonspecifically activated throughout the retina $(\mathbf{a}, \mathbf{c})$. The GFAP-positive cells did not demonstrate costaining for the presence of NPs. A diffuse red staining was observed in this layer, due to the released free Rh-6G. 
Figure 11. ESEM of eyes immediately after enucleation. Intravitreous injection of NPs was performed 1 hour before death. (a) A flow of NPs spread on the vitreous posteriorly (arrow) onto the retinal surface. (b) Numerous NPs were identified on the retinal surface (arrowhead) around retinal vessels (arrow).
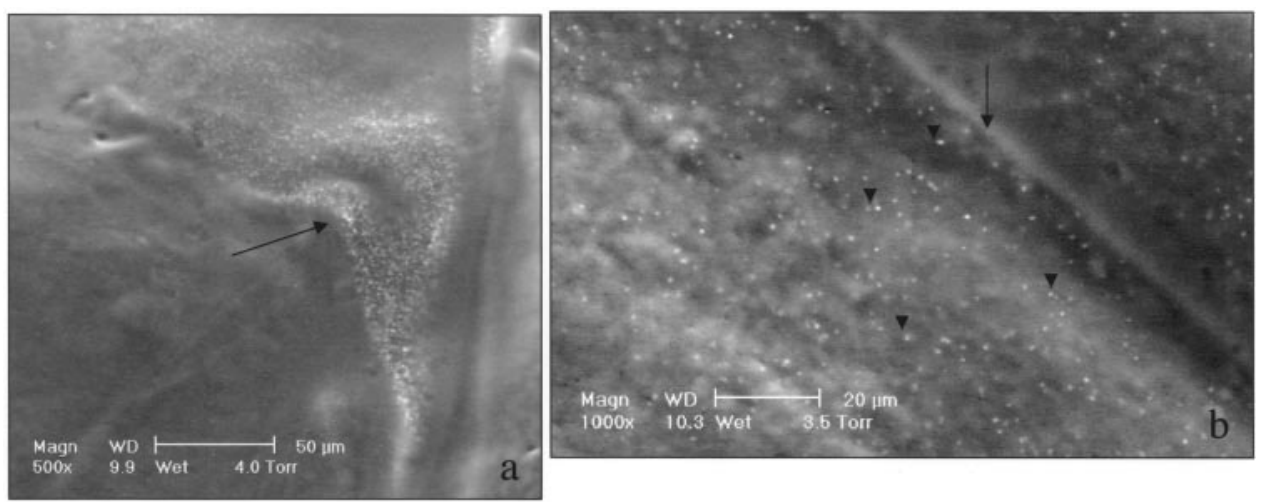

Although the intravitreous injections seemed to induce a nonspecific activation of the glial cells and a mild transient inflammatory reaction, the PLA NPs in vivo behavior, as reported in the present study can be used as a mean to convey drugs or plasmids targeted for the retina and the RPE.

\section{References}

1. Grizzi I, Garreau H, Li S, Vert M. Hydrolytic degradation of devices based on poly(DL-lactic acid) size-dependence. Biomaterials. 1995; 16:305-311.

2. Mainil-Varlet $P$, Curtis R, Gogolewski S. Effect of in vivo and in vitro degradation on molecular and mechanical properties of various low-molecular-weight polylactides. J Biomed Mater Res. 1997;36:360 -380.

3. Delie F, Berton M, Allemann E, Gurny R. Comparison of two methods of encapsulation of an oligonucleotide into poly(D,Llactic acid) particles. Int J Pharm. 2001;214:25-30.

4. Zambaux MF, Bonneaux F, Gref R, Dellacherie E, Vigneron C. Protein C-loaded monomethoxypoly (ethylene oxide)-poly(lactic acid) nanoparticles. Int J Pharm. 2001;212:1-9.

5. Alleman E, Leroux J, Gurny R. Polymeric nano and microparticles for the oral delivery of peptides and peptidomimetics. Adv Drug Deliv Rev. 1998;34:171-183.

6. Li Y, Pei Y, Zhang X, et al. PEGylated PLGA nanoparticles as protein carriers: synthesis, preparation and biodistribution in rats. J Control Release. 2001;71:203-211.

7. Cohen H, Levy RJ, Gao J, et al. Sustained delivery and expression of DNA encapsulated in polymeric nanoparticles. Gene Ther. 2000; 7:1896-1905.

8. Moghimi SM, Hunter AC, Murray JC. Long-circulating and targetspecific nanoparticles: theory to practice. Pharmacol Rev. 2001; 53:283-318.

9. Jacobs C, Kayser O. Nanosuspensions as particulate drug formulations in therapy: rationale for development and what we can expect for the future. Adv Drug Deliv Rev. 2001;47:3-19.

10. McClean S, Prosser E, Meehan E, et al. Binding and uptake of biodegradable poly-DL-lactide micro- and nanoparticles in intestinal epithelia. Eur J Pharm Sci. 1998;6:153-163.

11. Calvo P, Sanchez A., Martinez J, et al. Polyester nanocapsules as new topical delivery systems for Cyclosporin A. Pharm Res. 1996; 13:311-315.

12. Calvo $\mathrm{P}$, Vila-Jato JL, Alonso M. Comparative in vitro evaluation of several colloidal systems, nanoparticles, nanocapsules and nanoemulsions, as drug carriers. J Pharm Sci. 1996;85:530-536.
13. Calvo P, Thomas C, Alonson MJ, Vila-Jato JL, Robinson J. Study of the mechanism of interaction of poly( $\epsilon$-coprolactone) nanocapsules with the cornea by confocal laser scanning microscopy. Int J Pharm. 1994;103:283-291.

14. Gautier S, Grudzielski N, Goffinet G, et al. Preparation of poly(D,Llactide) nanoparticles assisted by amphophilic poly(methyl methacrylate-co-methacrylic acid) copolymers. J Biomater Sci Polym. 2001;12:429-450.

15. Scholes PD, Coombes AGA, Illum L, Davis SS, Vert M, Davies MC. The preparation of sub-200 $\mathrm{nm}$ poly(lactide-co-glycolide) microspheres for site-specific drug delivery. J Control Release. 1993;25: $145-153$

16. De Jaeghere F, Allémann E., Leroux JC, et al. Formulation and lyoprotection of poly(lactic acid-co-ethylene oxide) nanoparticles: influence on physical stability and in vitro cell uptake. Pharm Res. 1999;16:859-866.

17. Djano S, Martin-Iverson MT. Does locomotor response to novelty in rats predict susceptibility to develop sensitization to cocaine and PHNO? Behav Pharmacol. 2000;11:455-470.

18. Behar-Cohen FF, BenEzra D, Einmahl S, Gurny R. Challenges of intraocular drug delivery. Eur Pharm Rev. 2001;35-39.

19. Sakurai E, Ozeki H, Kunou N, Ogura Y. Effect of particle size of polymeric nanospheres on intravitreous kinetics. Ophthalmic Res. 2001;33:31-36.

20. Kimura H, Ogura Y, Moritera T, Honda Y, Tabata Y, Ikada Y. In vitro phagocytosis of polylactide microspheres by retinal pigment epithelial cells and intracellular drug release. Curr Eye Res. 1994; 13:353-360.

21. Ogura Y, Kimura H. Biodegradable polymer microspheres for targeted drug delivery to the retinal pigment epithelium. Surv Ophthalmol. 1995;39(suppl 1):S17-S24.

22. Galgut $\mathrm{P}$, Waite I, Smith R. Tissue reactions to biodegradable and non-degradable membranes placed transcutaneously in rats, observed longitudinally over a period of 4 weeks. J Oral Rehabil. 1996;23:17-21.

23. Gogolewski S, Jovanovic M, Perren SM, Dillon JG, Hughes MK. Tissue response and in vivo degradation of selected polyhydroxyacids: polylactides (PLA), poly(3-hydroxybutyrate) (PHB), and poly(3- hydroxybutyrate-co-3-hydroxyvalerate) (PHB/ VA). J Biomed Mater Res. 1993;27:1135-1148.

24. Kobayashi H, Shiraki K, Ikada Y. Toxicity test of biodegradable polymers by implantation in rabbit cornea. J Biomed Mater Res. 1992;26:1463-1476. 